\title{
El Embarazo y la COVID-19
}

\section{Pregnancy and COVID-19}

Ha pasado poco más de un año desde el inicio de la pandemia y más de 150 millones de personas han sido infectadas por SARS-Cov-2 ${ }^{(1)}$. Varios estudios han reportado un mayor riesgo de complicaciones maternas y fetales asociado a la infección por SARS-Cov-2 durante el embarazo ${ }^{(2)}$, a diferencia de la población no gestante, la población obstétrica con COVID-19, y mayor riesgo de presentar un cuadro severo y mayor probabilidad de requerir hospitalización en cuidados intensivos y ventilación mecánica ${ }^{(3)}$.

La sintomatología de COVID-19 en personas gestantes es similar a la de la población general. La mayoría de pacientes reportan tos, dolor de garganta, mialgias o fiebre como el primer síntoma; asimismo, los síntomas que llevan a las personas gestantes a buscar atención médica suelen ser tos, fatiga y mialgias, en la mayoría de casos ${ }^{(4)}$. Algunos de los síntomas de COVID-19 son similares a los síntomas comunes en el embarazo, por lo que la infección podría pasar desapercibida al inicio. En aproximadamente $25 \%$ de las pacientes gestantes, los síntomas pueded persistir hasta más de 8 semanas del inicio del cuadro ${ }^{(4)}$.

Las gestantes con COVID-19 tienen 3 veces más probabilidades de ser hospitalizadas en la unidad de cuidados intensivos y 2,9 veces más probabilidades de requerir ventilación mecánica, en comparación a personas no gestantes con COVID-19. Además, hay un aumento en $70 \%$ del riesgo de muerte de la madre ${ }^{(3)}$. Existe una asociación entre la severidad del cuadro de COVID-19 y la presencia de comorbilidades maternas como diabetes pregestacional, hipertensión y obesidad ${ }^{(5)}$.

Las gestantes infectadas por SARS-Cov-2 tienen más riesgo de presentar desórdenes hipertensivos del embarazo que las gestantes $\sin$ COVID-19 (2).

Los embarazos de pacientes con COVID-19 tambien muestran un incremento de partos preterminos y cesáreas. En la mayoría de casos, la causa del parto pretérmino es iatrogénica, debido a la condición materna ${ }^{(6)}$. El mayor riesgo de parto pretérmino en pacientes con COVID-19 se traduce en complicaciones neonatales asociadas a dicha prematuridad y este riesgo es aún mayor cuando el recién nacido también está infectado con COVID-19 (2). La tasa de cesáreas aumenta en el grupo de gestantes con COVID-19, especialmente cuando el cuadro es más severo ${ }^{(5)}$.

Un estudio reciente mostró que el examen histológico de placentas de madres con COVID-19, se evidenciaron cambios inflamatorios y vasculares que sugieren afección de la placenta por parte del virus ${ }^{(7)}$. Estos cambios pueden ser atribuidos a la hipoxia materna y a la actividad protrombótica producto de la liberación de citoquinas proinflamatorias inducida por el virus ${ }^{(7)}$.

La transmisión vertical del virus es posible pero poco frecuente. A la fecha, se han publicado reportes de casos en que la infección intrauterina fue comprobada. En la mayoría de los otros casos reportados donde los neonatos presentaban prueba molecular positiva, no se podía descartar que el contagió se dio luego del parto ${ }^{(8)}$. La lactancia materna no es por lo general una fuente de transmisión de COVID-19 y no debe ser interrumpida, pues no se ha encontrado virus en la gran mayoría de muestras de leche materna ${ }^{(9)}$, sin embargo, sí se han encontrado anticuerpos contra SARS-Cov-2 en la leche materna ${ }^{(10)}$, lo cual sugiere que la lactancia materna puede conferir inmunidad contra COVID-19 al recién nacido; la madre debe de usar mascarilla durante la lactancia, además de una adecuada higiene de manos y mamas.

La estrategia más importante para evitar estas complicaciones sigue siendo la prevención del contagio. Las gestantes, como grupo de riesgo, deben practicar el distanciamiento social, usar mascarilla y realizar la higiene de 
manos frecuentemente ${ }^{(3)}$. Por otro lado, la vacunación ha demostrado una reducción significativa en el desarrollo de enfermedad severa y mortalidad por COVID-19. Lamentablemente, las mujeres gestantes fueron excluidas de los estudios inciales. Aún sin datos recolectados en los estudios randomizados, la vacuna contra la COVID-19 no debe ser negada a las gestantes, ya que estas presentan un mayor riesgo de complicaciones al infectarse con COVID-19. Los primeros reportes de vacunación en gestantes ya han sido publicados. El reporte de vigilancia de efectos adversos de las vacunas de BioTech-Pfizer y Moderna mostró similar frecuencia de reacciones adversas a la vacuna en gestantes que en no gestantes. Estas fueron principalmente dolor en la zona de punción, fatiga, cefalea y mialgias. Los casos de aborto espontáneo y óbito fetal en gestantes vacunadas no fueron mayores a la prevalencia en la población general de gestantes. Asimismo, las complicaciones neonatales como parto pretérmino, tamaño pequeño para edad gestacional, anormalidades congénitas o muerte neonatal no fueron mayores que la prevalencia ya conocida. Además, hay evidencia de transferencia a través de la placenta de anticuerpos contra SARS-Cov-2 al feto ${ }^{(11)}$. Por lo tanto, se recomienda explicar a la persona gestante los potenciales efectos adversos y beneficios de la vacunación, junto con los riesgos de la infección por SARS-Cov-2 en el embarazo, para que la persona gestante pueda tomar una decisión informada.

El manejo de una paciente gestante con COVID debe tener un enfoque multidisciplinario. Con respecto al tratamiento farmacológico en pacientes gestantes es similar al manejo usual. La evidencia sugiere que es seguro usar sulfato de magnesio para la prevención de convulsiones o neuroprotección ante amenaza de parto prematuro. De manera similar, se puede dar un curso de corticoides para maduración pulmonar si es indicado. La administración de aspirina a bajas dosis puede ser mantenida en las personas gestantes con factores de riesgo de preeclampsia. El uso de anticoagulación profiláctica o de tratamiento no se requiere de manera generalizada, pero se debe evaluar cada caso individualmente y considerar el estado de hipercoagubilidad propio del embarazo ${ }^{(12)}$.

Finalmente, es muy importante tener en cuenta el mayor riesgo que involucra la infección por SARS-Cov-2 en el embarazo y hacer énfasis en la prevención en las personas gestantes. Los controles prenatales son de suma importancia y no deben verse suspendidos por el riesgo de infección, sino ser adaptados a una combinación de telemedicina y visitas presenciales con los controles ecográficos necesarios.

Maria Claudia Mauricio ${ }^{1}$, Mauricio La Rosa ${ }^{1,2,3}$

\section{REFERENCIAS BIBLIOGRÁFICAS}

1. Center for Systems Science and Engineering, Johns Hopkins University. COVID-19 Dashboard. Baltimore: Johns Hopkins University; 2021. (Citado el 13 de mayo del 2021). Disponible en: https:// coronavirus.jhu.edu/map.html

2. Villar J, Ariff S, Gunier R, et al. Maternal and Neonatal Morbidity and Mortality Among Pregnant Women With and Without COVID-19 Infection: The INTERCOVID Multinational Cohort Study. JAMA Pediatr. 2021;e211050. doi: 10.1001/ jamapediatrics.2021.1050

3. Zambrano L, Ellington S, Strid P, et al. Update: Characteristics of Symptomatic Women of Reproductive Age with Laboratory-Confirmed SARS-CoV-2 Infection by Pregnancy Status United States, January 22-October 3, 2020. MMWR Weekly. 2020; 69(44);1641-1647. (Citado el 13 de mayo del 2021). Disponible en: https://www.cdc. gov/mmwr/volumes/69/wr/mm6944e3.htm

4. Asphar Y, Gaw S, Flaherman V, et al. Clinical Presentation of Coronavirus Disease 2019 (COVID-19) in Pregnant and Recently Pregnant People. Obstet Gynecol. 2020 ; 136(6):1117-1125. doi: 10.1097/AOG.0000000000004178.

5. Adhikari E, Moreno W, Zofkie A, et al. Pregnancy Outcomes Among Women With and Without Severe Acute Respiratory Syndrome Coronavirus 2 Infection. JAMA Netw Open. 2020 ;3(11):e2029256. doi: 10.1001/jamanetworkopen.2020.29256

6. Elsaddiga M, Khalil A. Effects of the COVID pandemic on pregnancy outcomes. Best Pract Res Clin Obstet Gynaecol. 2021;1:S1521-6934(21)000432.doi: 10.1016/j.bpobgyn.2021.03.004

7. Prochaska E, Jang M, Burd I. COVID-19 in pregnancy: Placental and neonatal involvement. Am J Reprod Immunol. 2020;84(5):e13306. doi: 10.1111/

\footnotetext{
Universidad Peruana Cayetano Heredia. Lima, Perú

Unidad de Medicina Materno Fetal, Clínica Anglo Americana. Lima, Perú

University of Texas Medical Branch. Texas, USA.
} 
aji.13306

8. Kotlyar A, Grechukhina O, Chen A, et al. Vertical transmission of coronavirus disease 2019: a systematic review and meta-analysis. Am J Obstet Gynecol. 2021;224(1):35-53.e3. doi: 10.1016/j.ajog.2020.07. 049

9. Wenling Y, Junchao Q, Xiao Z, Ouyang S. Pregnancy and COVID-19: management and challenges. Rev Inst Med Trop Sao Paulo. 2020;62:e62. doi: 10.1590/ s1678-9946202062062

10. Haia-Perl S,Uzan-Yulzari A,Klainer $\mathrm{H}$, et al. SARS-CoV-2-Specific Antibodies in Breast Milk
After COVID-19 Vaccination of Breastfeeding Women. JAMA. 2021;e215782. doi: 10.1001/ jama.2021.5782

11. Shimabukuro T, Kim S, Myers T, et al. Preliminary Findings of mRNA Covid-19 Vaccine Safety in Pregnant Persons.N Engl J Med. 2021. doi: 10.1056/ NEJMoa2104983

12. D’Souza R, R Ashraf R, H Rowe H, et al. Pregnancy and COVID-19: pharmacologic considerations. Ultrasound Obstet Gynecol. 2021;57(2):195-203. doi: 10.1002/uog.23116 